\title{
Allicin inhibits tubular epithelial-myofibroblast transdifferentiation under high glucose conditions in vitro
}

\author{
HONG HUANG ${ }^{1}$, FENPING ZHENG $^{2}$, XUEHONG DONG $^{2}$, FANG WU $^{2}$, TIANFENG WU $^{1}$ and HONG LI ${ }^{2}$ \\ ${ }^{1}$ Department of Endocrinology, Zhejiang Hospital, Hangzhou, Zhejiang 310013; ${ }^{2}$ Department of Endocrinology, \\ The Affiliated Sir Run Run Shaw Hospital, School of Medicine, Zhejiang University, Hangzhou, Zhejiang 310016, P.R. China
}

Received April 9, 2015; Accepted May 4, 2016

DOI: $10.3892 /$ etm.2016.3913

\begin{abstract}
Previous studies have suggested that tubular epithelial-mesenchymal transition (EMT) is an important event in renal tubulointerstitial fibrosis, which is a clinical characteristic of diabetic nephropathy. The present study aimed to investigate the effect of allicin, the major biological active component of garlic, on the EMT of a human renal proximal tubular epithelial cell line (HK-2) cultured under high glucose concentrations. HK-2 cells were exposed for $48 \mathrm{~h}$ to 5.5 or $25 \mathrm{mmol} / \mathrm{l} \mathrm{D}$-glucose, $25 \mathrm{mmol} / 1 \mathrm{D}$-glucose plus allicin (2.5, 5,10 or $20 \mu \mathrm{g} / \mathrm{ml}$ ) or $25 \mathrm{mmol} / \mathrm{l}$ D-glucose plus $20 \mu \mathrm{mol} / 1$ PD98059, a selective inhibitor of the mitogen activated protein kinase/extracellular signal-regulated kinase (ERK) signaling pathway. The EMT of HK-2 cells was assessed by analyzing the protein expression of E-cadherin, $\alpha$-smooth muscle actin $(\alpha-\mathrm{SMA})$, vimentin and collagen I via immunocytochemistry. In addition, reverse transcription-quantitative polymerase chain reaction and western blotting were used to detect the expression levels of transforming growth factor (TGF)- $\beta 1$ and phosphorylated (p)-ERK1/2. Marked morphological changes were observed in HK-2 cells cultured under high glucose conditions, and these changes were abrogated by simultaneous incubation with allicin and PD98059. The expression levels of $\alpha$-SMA, vimentin and collagen I were significantly increased in HK-2 cells cultured under high glucose conditions, as compared with those cultured under normal glucose conditions $(\mathrm{P}<0.01)$. Conversely, the expression levels of E-cadherin were significantly decreased upon stimulation with high glucose $(\mathrm{P}<0.01)$. Furthermore, the expression levels of TGF- $\beta 1$ and $p-E R K 1 / 2$ were significantly upregulated in HK-2 cells cultured under high glucose conditions, as compared with those cultured under normal glucose conditions $(\mathrm{P}<0.05)$.
\end{abstract}

Correspondence to: Dr Hong Li, Department of Endocrinology, The Affiliated Sir Run Run Shaw Hospital, School of Medicine, Zhejiang University, 3 Qingchun East Road, Hangzhou, Zhejiang 310016, P.R. China

E-mail: lihongheyi@126.com

Key words: allicin, diabetic nephropathy, renal tubular epithelial cell, epithelial-myofibroblast transdifferentiation
Allicin partially reversed the high-glucose-induced increase in $\alpha$-SMA, vimentin and collagen I expression $(\mathrm{P}<0.01$ at $20 \mu \mathrm{g} / \mathrm{ml}$ ), increased the expression of E-cadherin, and significantly downregulated the high glucose-induced expression of TGF- $\beta 1$ and $p$-ERK1/2 in a dose-dependent manner $(\mathrm{P}<0.05)$. The results of the present study suggested that high glucose concentrations induced the EMT of HK-2 cells, and that allicin was able to inhibit the EMT, potentially via regulation of the ERK1/2-TGF- $\beta 1$ signaling pathway.

\section{Introduction}

Tubulointerstitial fibrosis, which is considered the final common pathway of progressive kidney diseases and eventually leads to end-stage renal disease, is a result of the tubular epithelial-to-mesenchymal transition (EMT) and excessive accumulation of extracellular matrix (ECM) that characterize the majority of chronic kidney diseases, including diabetic nephropathy (DN) (1). Previous studies have demonstrated that high glucose conditions induce the EMT in renal proximal tubular cells in vitro and in vivo (2-5). In addition, it has been reported that myofibroblast formation is a critical step in the pathogenesis of tubulointerstitial fibrosis, and it has been shown to be a key step in DN progression $(5,6)$. Myofibroblasts, which are considered to be one of the principle effective cells derived from the renal tubular EMT, are responsible for the ECM and have a central role in progressive renal fibrosis $(7,8)$. In the process of the EMT, renal proximal tubular cells have been shown to contribute to renal interstitial fibrosis; the cells lose their epithelial phenotype and acquire a myofibroblastic phenotype, which is characterized by an increased motility, extracellular protein synthesis and invasiveness (9). Irrespective of the initial causes, interstitial fibrosis is a remarkable process that is characterized by de novo activation of the mesenchymal markers, $\alpha$-smooth muscle actin ( $\alpha$-SMA) and vimentin, and the excessive deposition of ECM components in the tubulointerstitium under pathological conditions by the myofibroblasts $(8,10,11)$. Therefore, it is important to investigate the molecular mechanisms underlying tubulointerstitial fibrosis in order to identify novel targets for the effective treatment, prevention and delay of DN.

The EMT is regulated by numerous growth factors and hormones (12). Transforming growth factor (TGF)- $\beta 1$ has been shown to be a potent growth factor that has a pivotal role 
in renal fibrogenesis and induces various biological effects via numerous signal transduction pathways $(8,13,14)$. At present, TGF- $\beta 1$ is recognized as the major cytokine responsible for the ECM pathology that accompanies DN (15).

The mitogen-activated protein kinase (MAPK) signaling pathway is one of the most important signal transduction pathways and is found widely in cells (16). Activation of extracellular signal-regulated kinase 1/2 (ERK1/2), a downstream signaling molecule of TGF- $\beta 1$ and the first member of the MAPK family to be identified, also has an important role in the progression of tubular EMT and renal fibrosis (17). Previous studies have demonstrated that TGF- $\beta 1$ induces the EMT primarily via the activation of MAPK and ERK in proximal tubular epithelial cells (18). Notably, the chemical inhibition of ERK1/2 was able to restrain the EMT process by inhibiting TGF- $\beta 1$ (18). These findings suggested that phosphorylated (p)-ERK1/2 blocking therapies may attenuate renal interstitial fibrosis.

Allicin is one of the most biologically active compounds of garlic (Allium sativum) (19), and its chemical structure is shown in Fig. 1. Allicin has a broad spectrum of physiological activities, including antimicrobial (20,21), antifungal (22), antioxidant (23), antihypertensive (24), cardioprotective (25-27), antiinflammatory (28), anticancer (29-32) and immunomodulatory (28) properties. Previous studies (33-36) have demonstrated that allicin may have a role in the prevention of tissue fibrosis, particularly in the liver, lungs and heart, by inhibiting fibroblast proliferation, fibrogenic cytokine secretion and ECM synthesis (37). The present study aimed to investigate the effects of allicin on high glucose-induced EMT in human tubule epithelial cells (HK-2) and the potential underlying mechanisms.

\section{Materials and methods}

Reagents and antibodies. Allicin (purity, >88.4\%), which is also known as diallyl thiosulfinate, was purchased from the China National Institute for Food and Drug Control (Beijing, China). Allicin was dissolved in serum-free culture medium (Jinuo Bio-Pharmaceutical Tech. Co. Ltd., Hangzhou, China) and further diluted to the recommended concentration (2.5, 5,10 or $20 \mu \mathrm{g} / \mathrm{ml}$ ) with culture medium. The HK-2 normal human renal tubular epithelial cell line was purchased from the American Type Culture Collection (Manassas, VA, USA). Human recombinant anti- $\alpha$-SMA (cat. no. BM0002; dilution 1:200), anti-collagen I (cat. no. PB0980; dilution 1:100) and anti-ERK1/2 (cat. no. BA1246; dilution 1:500) antibodies were purchased from Boster Biotechnology Inc. (Wuhan, China). Human recombinant anti-vimentin (cat. no. SC6260; dilution 1:200), anti-TGF- $\beta 1$ (cat. no. SC146; dilution 1:500) and anti-p-ERK1/2 (cat. no. SC16982; dilution 1:500) antibodies were purchased from Santa Cruz Biotechnology, Inc. (Dallas, TX, USA). Human recombinant anti-E-cadherin antibody was obtained from Epitomics (Burlingame, CA, USA; cat. no. 1702-1; dilution 1:200). PD98059, a selective inhibitor of the MAPK/ERK kinase, was purchased from Promega Corporation (Madison, WI, USA). The mouse anti- $\beta$-actin monoclonal antibody (cat. no. A5441; dilution 1:5,000) and other antibodies for the western blot analysis were purchased from Sigma-Aldrich (St. Louis, MO, USA). Fluorescein isothiocyanate (FITC)-conjugated anti-mouse (cat. no. 70-GAM001;

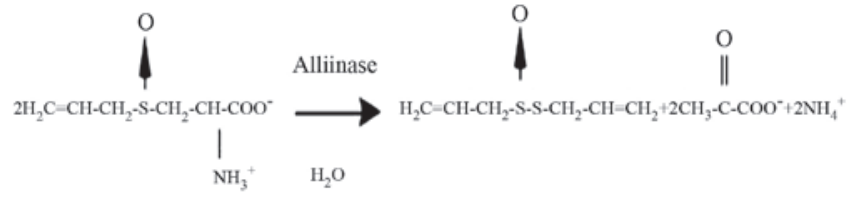

Alliin

Allicin

Pyruvic acid Ammonia

Figure 1. Chemical structure of allicin [S-(2-propenyl) 2-propene-1-sulfinothioateor diallyl thiosulfinate].

dilution, 1:200), anti-rabbit (cat. no. 70-GAR001; dilution, 1:200) and anti-goat (cat. no. 70-RAG001; dilution, 1:200) secondary antibodies were obtained from Liankebio Biomart, Inc., (Hangzhou, China). Horseradish peroxidase (HRP)-conjugated anti-mouse (cat. no. ZB-5305; dilution, 1:10,000), anti-rabbit (cat. no. ZB-5301; dilution, 1:10,000) and anti-goat (cat. no. ZB-5306; dilution, 1:10,000) secondary antibodies were obtained from Zhongshan Belling Biotechnology Co., Ltd. (Beijing, China). DAPI, used for nuclear staining, and RNA Extraction reagent were purchased from Thermo Fisher Scientific, Inc. (Waltham, MA, USA). The PCR primers, PrimeScript $^{\mathrm{TM}}$ RT Reagent kit and SYBR Premix Ex Taq kit were purchased from Takara Bio, Inc. (Otsu, Japan).

Cell culture. HK-2 cells from passages 3 to 5 were used throughout the studies. Cells were cultured at $37^{\circ} \mathrm{C}$ under $5 \%$ $\mathrm{CO}_{2}$ in Dulbecco's modified Eagle's medium: Nutrient Mixture F-12 (DMEM/F12; Thermo Fisher Scientific, Inc.) supplemented with $10 \%$ heat-inactivated fetal bovine serum (FBS; Biological Industries USA, Cromwell, CT, USA), $5.5 \mathrm{mmol} / 1$ D-glucose, glutamine and antibiotics (penicillin and streptomycin). Cells were grown on 6-well plates, on glass coverslips or on 10-cm dishes (Corning Life Sciences, Tokyo, Japan) to either $100 \%$ confluence or subconfluence, then subjected to various treatments. Briefly, i) in the normal glucose group, cells were cultured in DMEM supplemented with $5.5 \mathrm{mmol} / \mathrm{l}$ D-glucose (normal glucose); ii) in the high glucose group, cells were cultured in high glucose medium supplemented with $25 \mathrm{mmol} / \mathrm{l} \mathrm{D}$-glucose; iii) allicin (at concentrations of 2.5, 5, 10 or $20 \mu \mathrm{g} / \mathrm{ml}$ ) was added when the cell culture medium was changed from normal glucose to high glucose $(25 \mathrm{mmol} / \mathrm{l})$ medium; iv) PD98059 (at concentrations of $20 \mu \mathrm{mol} / \mathrm{l}$ ) was added when the cell culture medium was changed from normal glucose to high glucose $(25 \mathrm{mmol} / \mathrm{l})$ medium. HK-2 cells were passaged when $80 \%$ confluent. For experiments, subconfluent cells were incubated with serum-free medium for $24 \mathrm{~h}$ and divided into four groups, as follows: i) Normal glucose (5.5 mmol/1; control group); ii) high glucose group (25 mmol/l); iii) high glucose $(25 \mathrm{mmol} / \mathrm{l})$ plus allicin $(2.5,5$, 10 or $20 \mu \mathrm{g} / \mathrm{ml})$ group; and iv) high glucose $(25 \mathrm{mmol} / \mathrm{l})$ plus PD98059 $(20 \mu \mathrm{mol} / \mathrm{l})$ group. Following treatment, the cells were incubated for $48 \mathrm{~h}$ prior to harvesting and further experiments. Each experiment was repeated at least three times.

Reverse transcription-quantitative polymerase chain reaction (RT-qPCR). Total RNA was isolated from the cultured HK-2 cells using RNA Extraction reagent and RT-qPCR was performed according to a previous study (38). Briefly, total RNA (500 ng) was reverse transcribed into cDNA using the 

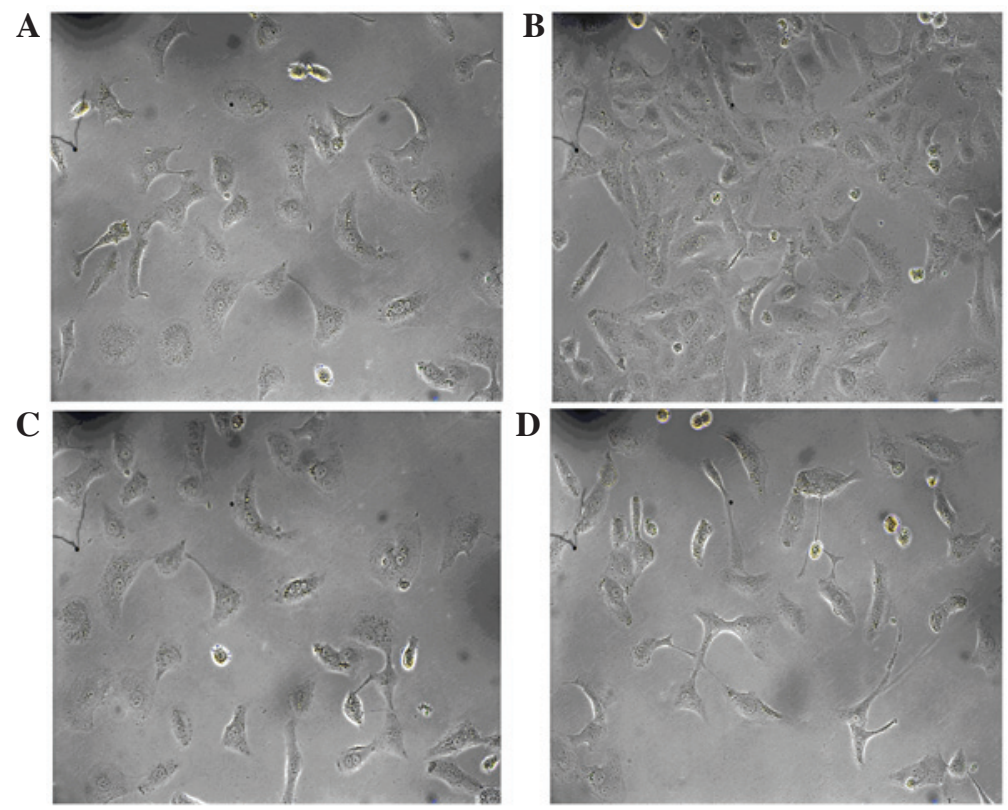

Figure 2. Effect of allicin on high glucose-induced morphological changes in HK-2 cells at $48 \mathrm{~h}$. Phase-contrast microscopy images are presented, showing the morphology of HK-2 cells following exposure to (A) normal glucose (control), (B) high glucose, (C) high glucose plus $20 \mu \mathrm{g} / \mathrm{ml}$ allicin or (D) high glucose plus $20 \mu \mathrm{mol} / 1$ PD98059. (magnification, x200).

ThermoScript ${ }^{\mathrm{TM}}$ RT-PCR System (Thermo Fisher Scientific, Inc.), after which qPCR was performed using the SYBR Premix Ex Taq kit and PCR primers on an ABI Prism 7500 thermal cycler (Applied Biosystems; Thermo Fisher Scientific, Inc.), according to manufacturer's protocol. The PCR cycling conditions were as follows: $95^{\circ} \mathrm{C}$ for $5 \mathrm{~min}$, followed by 40 cycles at $95^{\circ} \mathrm{C}$ for $15 \mathrm{sec}, 60^{\circ} \mathrm{C}$ for $20 \mathrm{sec}$ and $72^{\circ} \mathrm{C}$ for $20 \mathrm{sec}$, and a final extension at $72^{\circ} \mathrm{C}$ for $10 \mathrm{~min}$. The primer sequences were: TGF- $\beta 1$ (362 bp) forward, 5'-ACTACGCCA AAG AAGTCACCC-3' and reverse, 5'-AAGCCCTGTATT CCGTCTCC-3'; and $\beta$-actin (317 bp) forward, 5'-CGTACC ACTGGCATTGTGAT-3' and reverse, 5'-TTGCCGATA GTGATGACCTG-3'. Reaction specificity was confirmed by agarose gel electrophoresis analysis of PCR products. Ratios for TGF- $\beta 1 / \beta$-actin mRNA were calculated for each sample and are expressed as the mean \pm standard error of the mean. Each sample was run in triplicate. The expression of each gene was normalized against that of $\beta$-actin. The relative quantity of mRNA was calculated using the $2^{-\Delta \Delta \mathrm{Cq}}$ method (39).

Western blotting. HK-2 cells were plated in 10 -cm culture plates with or without stimuli and various treatments: HK-2 cells were passaged until $80 \%$ confluent. Subconfluent cells were incubated with serum-free medium for $24 \mathrm{~h}$ and divided into four groups, as follows: i) Normal glucose group $(5.5 \mathrm{mmol} / \mathrm{l}$; control group); ii) high glucose group ( $25 \mathrm{mmol} / \mathrm{l})$; iii) high glucose $(25 \mathrm{mmol} / \mathrm{l})$ and allicin $(2.5,5,10$ or $20 \mu \mathrm{g} / \mathrm{ml})$ group; and iv) high glucose $(25 \mathrm{mmol} / \mathrm{l})$ and PD98059 (20 $\mu \mathrm{mol} / \mathrm{l})$ group. Following treatment, the cells were incubated for $48 \mathrm{~h}$. The cells were then analyzed by western blotting, as described previously (40). Cells were collected and lysed using lysis buffer [20 mM Tris- $\mathrm{HCl}(\mathrm{pH} 7.5), 150 \mathrm{mM} \mathrm{NaCl}, 1 \mathrm{mM}$ EDTA, $1 \%$ Triton, $1 \%$ NP-40, $2.5 \mathrm{mM}$ sodium pyrophosphate, $1 \mathrm{mM} \beta$-glycerophosphate, $1 \mathrm{mM}$ leupeptin, $1 \mathrm{mM}$ phenylmethylsulfonyl fluoride], and samples were centrifuged at
$12,000 \mathrm{xg}$ for $30 \mathrm{~min}$ at $4^{\circ} \mathrm{C}$. The concentration of protein in each cell lysate was determined using a BCA Protein Assay kit (Pierce; Thermo Fisher Scientific, Inc.). Equal quantities of cell protein lysates $(20 \mu \mathrm{g})$ were mixed with $2 \mathrm{X}$ sodium dodecyl sulfate (SDS) loading buffer containing dithiothreitol and heated at $100^{\circ} \mathrm{C}$ for $10 \mathrm{~min}$, prior to separation by $10 \%$ SDS-PAGE. Subsequently, the proteins were transferred to a polyvinylidene difluoride membrane and non-specific binding was blocked with 5\% non-fat dry milk in phosphate-buffered saline containing $0.02 \% \mathrm{v} / \mathrm{v}$ Tween-20. The membrane was incubated overnight at $4^{\circ} \mathrm{C}$ with one of the following primary antibodies: Rabbit anti-p-ERK1/2 (1:500), anti-ERK1/2 (1:500) and anti-TGF- $\beta 1$ (1:500) polyclonal antibodies, and mouse anti- $\beta$-actin monoclonal antibody $(1: 5,000)$. After three washes with Tris-buffered saline with Tween 20, the membranes were incubated for $2 \mathrm{~h}$ at room temperature with HRP-conjugated anti-rabbit or anti-mouse IgG $(1: 10,000)$. After further washing, the membrane was detected with ECL chemiluminescence, and band intensities were quantified by densitometry using Image Lab software (Bio-Rad Laboratories, Inc., Hercules, CA, USA). $\beta$-actin was used as a loading control.

Immunocytochemistry. HK-2 cells in the various groups were analyzed for tubular EMT using microwave-based two-color immunostaining. Briefly, cells were fixed in $4 \%$ paraformaldehyde and pre-incubated with $10 \%$ FBS and $10 \%$ normal goat serum (Bejing Zhongshan Golden Bridge Biotechnology Co., Ltd., Beijing, China) to block non-specific binding. Subsequently, the cells were incubated with rabbit anti- $\alpha$-SMA, rabbit anti-vimentin, mouse anti-E-cadherin and mouse anti-collagen I monoclonal antibodies or an isotype control $\mathrm{IgG}$ at $4^{\circ} \mathrm{C}$ overnight. Following inactivation of endogenous peroxidase activity, the cells were incubated with HRP-conjugated goat anti-rabbit or goat anti-mouse $\mathrm{IgG}$, then by rabbit or mouse anti-peroxidase complexes. Slides 
were then developed with 3,3'-diaminobenzidine to produce a brown product. Finally, all sections were counterstained with hematoxylin and mounted on cover-slips using aqueous mounting medium. All procedures were performed at room temperature. Brown-yellow granules, as assessed by light microscopy, were regarded as positive cells. Images were analyzed using Image-Pro Plus 6.0 image analysis software (Media Cybernetics, Inc., Rockville, MD, USA). The stained field sections were then assessed for morphological changes using a light microscope at x400 magnification. For all groups, sections were taken from the same region. An average gray-scale value represented the measurement value. The gray-scale value of positive protein expression was determined and statistically analyzed.

Fluorescence immunocytochemistry. HK-2 cells were cultured in DMEM containing $5.5 \mathrm{mmol} / \mathrm{l} \mathrm{D}$-glucose. Upon reaching $80 \%$ confluence, cells were synchronized with FBS-free medium (5.5 mmol/l D-glucose) for $24 \mathrm{~h}$, then cultured with or without various treatments for $48 \mathrm{~h}$. Subconfluent cells were incubated with serum-free medium for $24 \mathrm{~h}$ and divided into four groups, as follows: i) Normal glucose $(5.5 \mathrm{mmol} / \mathrm{l}$; control group); ii) high glucose group (25 mmol/l); iii) high glucose $(25 \mathrm{mmol} / \mathrm{l})$ plus allicin $(2.5,5,10$ or $20 \mu \mathrm{g} / \mathrm{ml})$ group; and iv) high glucose (25 mmol/l) plus PD98059 (20 $\mu \mathrm{mol} / \mathrm{l})$ group. Following treatment, the cells were incubated for $48 \mathrm{~h}$. Cells were then fixed in $4 \%$ paraformaldehyde for $30 \mathrm{~min}$, permeabilized with $0.1 \%$ Triton X-100 for $15 \mathrm{~min}$ and incubated with $10 \%$ normal goat serum blocking buffer for $1 \mathrm{~h}$ at $37^{\circ} \mathrm{C}$. Subsequently, the cells were incubated overnight at $4^{\circ} \mathrm{C}$ with rabbit anti- $\alpha$-SMA (1:200), rabbit anti-vimentin (1:200), mouse anti-E-cadherin (1:200) and mouse anti-collagen I (1:100) monoclonal antibodies. Cells were then incubated with FITC-conjugated secondary antibody $(1: 200)$ for $1 \mathrm{~h}$ at $37^{\circ} \mathrm{C}$ in the dark, then stained with propidium iodide for $1 \mathrm{~h}$. The negative control consisted of cells incubated with IgG instead of primary antibody. Cells were visualized and photographed using a laser scanning confocal microscope (Olympus Corp., Tokyo, Japan). Olympus FluoView (Olympus Corp.) and Velocity 4.1 (Improvision; Velocity Software Inc, Mountain View, CA, USA) software were used for image processing, deconvolution, and quantitative imaging analyses wherever appropriate. Confocal images acquired under the identical exposure time and instrument settings among different groups were used for colocalization and quantitative fluorescence intensity analyses.

Statistical analysis. Data are expressed as the mean \pm standard error of the mean. Statistical significance was determined using one-way analysis of variance followed by Fisher's least significant difference test. Statistical analyses were performed using SPSS 16.0 software for Windows (SPSS, Inc., Chicago, IL, USA). $\mathrm{P}<0.05$ was considered to indicate a statistically significant difference.

\section{Results}

Effect of allicin on high glucose-induced morphological changes in HK-2 cells. To assess the effect of allicin on cell morphology, HK-2 cells were serum deprived for $24 \mathrm{~h}$ and exposed to high glucose conditions for $48 \mathrm{~h}$, after which the cells were observed by inverted phase-contrast microscopy. The normal group had the typical epithelial cuboidal shape, with a cobblestone morphology (Fig. 2A). Conversely, cells in the high glucose group exhibited an elongated, fibroblast-like phenotype (Fig. 2B). Simultaneous incubation with allicin $(20 \mu \mathrm{g} / \mathrm{ml})$ or PD98059 $(20 \mu \mathrm{g} / \mathrm{ml})$ prevented the high glucose-induced morphological changes in the majority of cells, with cells retaining epithelial polarity and a cobblestone growth pattern, in the absence of hypertrophy and an elongated morphology (Fig. 2C and D).

Effect of allicin on the expression levels of E-cadherin, $\alpha-S M A$, vimentin and collagen I in HK-2 cells cultured under high glucose conditions. To confirm the transformation of HK-2 cells into a fibroblast-like phenotype, the expression levels of the epithelial marker, E-cadherin, and the mesenchymal markers, $\alpha$-SMA and vimentin, were determined by immunohistochemistry and fluorescence immunocytochemistry. In addition, the expression levels of collagen I, an important component of the ECM, were also evaluated. The expression levels of $\alpha$-SMA, vimentin and collagen I were significantly increased and peaked at $48 \mathrm{~h}$ in the high glucose group, as compared with the control group $(\mathrm{P}<0.01$; Figs. 3 and 4$)$. Conversely, the expression levels of E-cadherin were markedly decreased in the high glucose group, as compared with the control group ( $\mathrm{P}<0.01$; Figs. 3 and 4$)$. Allicin reversed the high glucose-induced changes at $48 \mathrm{~h}$ in a dose-dependent manner, with the difference being significant at $20 \mu \mathrm{g} / \mathrm{ml}$ allicin ( $\mathrm{P}<0.01$ vs. the high glucose group). Upon incubation with PD98059 for $48 \mathrm{~h}$, the expression levels of $\alpha$-SMA, vimentin and collagen I were markedly decreased and those of E-cadherin were markedly increased, as compared with those of the high glucose cells $(\mathrm{P}<0.01)$, although they were not significantly different from the control cells $(\mathrm{P}>0.05)$.

Effect of allicin on the expression level of TGF- $\beta 1$ in HK-2 cells cultured under high glucose conditions. The mRNA and protein expression levels of TGF- $\beta 1$ were measured by RT-qPCR and western blotting, respectively (Fig. 5). RT-qPCR demonstrated that the mRNA expression levels of TGF- $\beta 1$ were significantly increased at $48 \mathrm{~h}$ in the high glucose group, as compared with the control group $(\mathrm{P}<0.05)$. Allicin treatment resulted in a dose-dependent decrease in the mRNA expression levels of TGF- $\beta 1$ at $48 \mathrm{~h}$; in particular the differences were significant at 10 and $20 \mu \mathrm{g} / \mathrm{ml}$ allicin ( $\mathrm{P}<0.05$ vs. the high glucose group). Upon intervention with PD98059, the mRNA expression levels of TGF- $\beta 1$ were significantly reduced, as compared with the high glucose group $(\mathrm{P}<0.05)$, although they were increased, as compared with the normal control cells $(\mathrm{P}<0.05)$. These results were consistent with the results of the western blot analysis. The protein expression levels of TGF- $\beta 1$ were significantly increased and peaked at $48 \mathrm{~h}$ in the high glucose group, as compared with the control group $(\mathrm{P}<0.05)$. Allicin decreased the protein expression levels of TGF- $\beta 1$ at $48 \mathrm{~h}$ in a dose-dependent manner, in particular at $20 \mu \mathrm{g} / \mathrm{ml}$ where the inhibition rate was $55.7 \%$, as compared with the high glucose group $(\mathrm{P}<0.05)$. Upon intervention with PD98059, the protein expression levels of TGF- $\beta 1$ were also significantly reduced, 
A
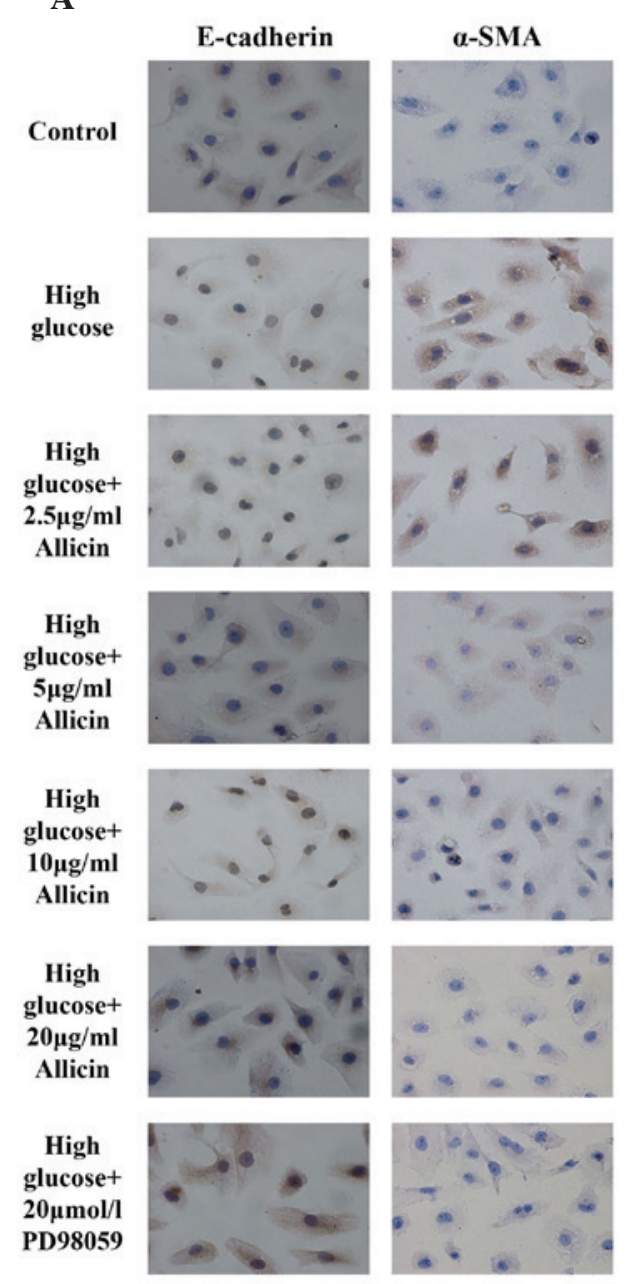
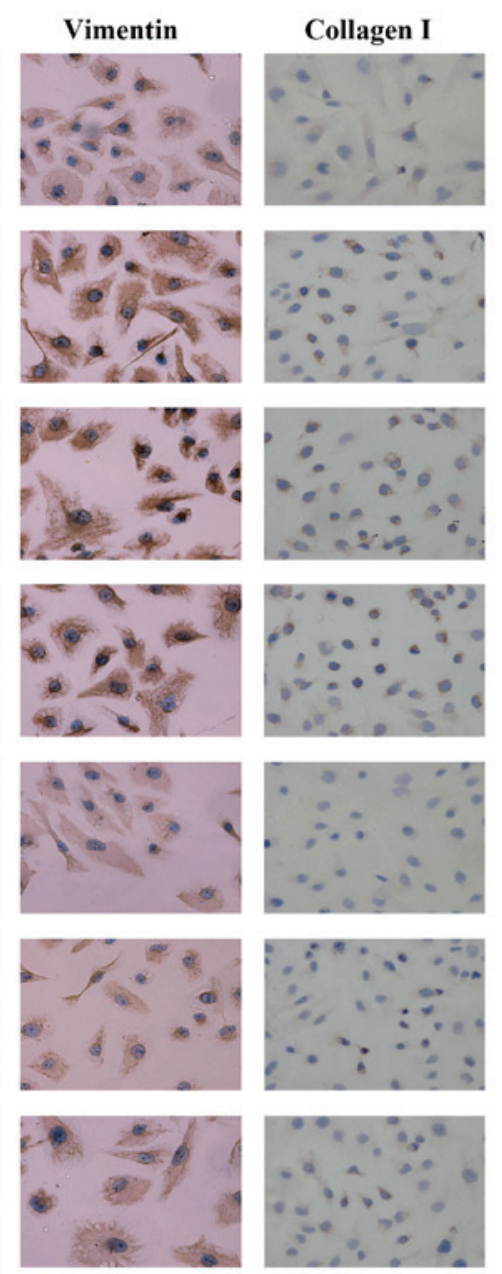

B
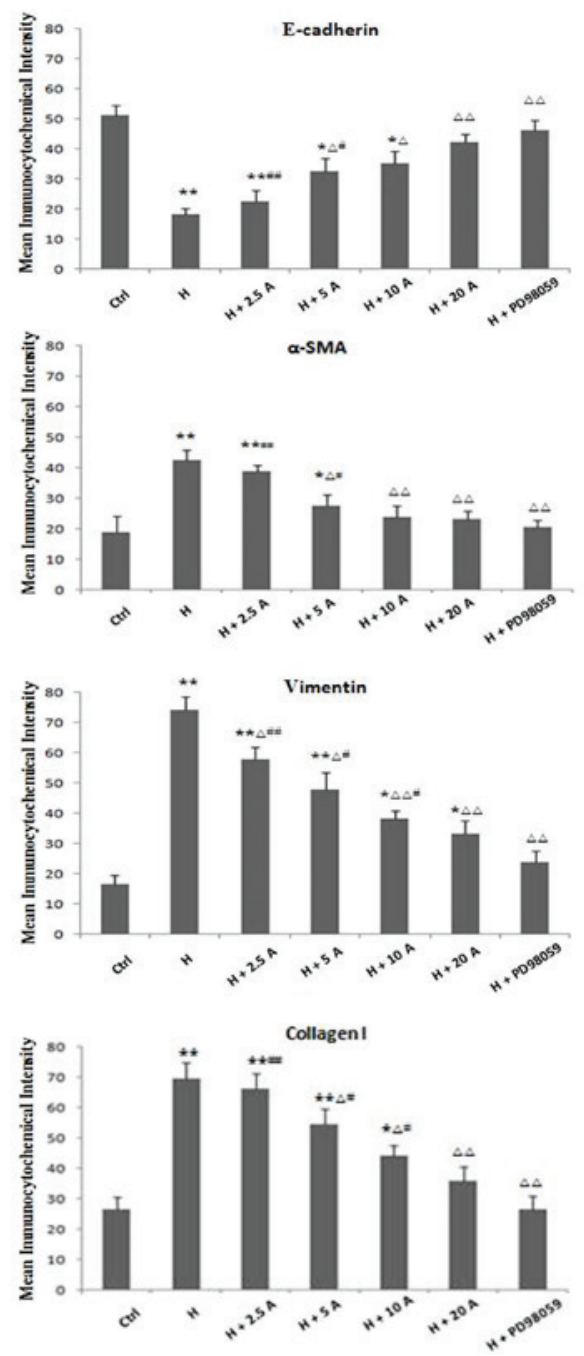

Figure 3. (A) Immunocytochemical staining of E-cadherin, $\alpha$-SMA, vimentin and collagen I in HK-2 cells cultured for 48 h (magnification, $\mathrm{x} 200$ ). (B) HK-2 cells were exposed to normal glucose (ctrl), high glucose, high glucose plus $2.5,5,10$ and $20 \mu \mathrm{g} / \mathrm{ml}$ allicin or high glucose plus $20 \mu$ mol/1 PD98059. $\mathrm{P}<0.05$ and ${ }^{* *} \mathrm{P}<0.01$ vs. Ctrl; ${ }^{\Delta} \mathrm{P}<0.05$ and ${ }^{\Delta \Delta} \mathrm{P}<0.01$ vs. $\mathrm{H} ;{ }^{\#} \mathrm{P}<0.05$ and ${ }^{\# \#} \mathrm{P}<0.01$ vs. $\mathrm{H}+\mathrm{PD} 98059 . \alpha-$ SMA, $\alpha$-smooth muscle actin; Ctrl, control; H, high glucose; A, allicin.

as compared with the high glucose group $(\mathrm{P}<0.05)$, and were not significantly different, as compared with the control group $(\mathrm{P}>0.05)$.

Effect of allicin on p-ERK1/2 expression in HK-2 cells cultured under high glucose conditions. To further elucidate the molecular mechanisms underlying the allicin-mediated inhibition of the EMT process in HK-2 cells cultured under high glucose conditions, the potential involvement of the ERK1/2 signaling pathway was investigated by western blotting. The levels of p-ERK1/2 were significantly increased in the high glucose group at $48 \mathrm{~h}$, as compared with the control group $(\mathrm{P}<0.05$; Fig. 6). However, high glucose-induced ERK1/2 phosphorylation was significantly attenuated by pre-treatment with PD98059 ( $\mathrm{P}<0.05$; Fig. 6), a specific inhibitor of the MAPK/ERK kinase, which is the upstream activator of ERK1/2. Similarly, treatment with allicin significantly decreased the protein expression levels of p-ERK1/2 in a dose-dependent manner, in particular at $20 \mu \mathrm{g} / \mathrm{ml}$, with inhibition rates of $37.7 \%$, as compared with the high glucose group $(\mathrm{P}<0.05)$. However, the levels were significantly increased, as compared with the control group $(\mathrm{P}<0.05)$.

\section{Discussion}

The EMT is a key process in tissue development, carcinogenesis and organ fibrosis (41). In addition, it has emerged as a central mechanism underlying tubulointerstitial fibrosis, a progressive pathology common to numerous chronic kidney diseases, including DN $(8,42)$. Interstitial myofibroblasts have a critical role in the development of tubulointerstitial fibrosis in diabetic and non-diabetic kidney diseases (43). A large proportion of interstitial myofibroblasts originate from transformed tubular epithelial cells experiencing pathological conditions during renal fibrogenesis (44). Interstitial fibrosis is characterized by de novo activation of $\alpha$-SMA and vimentin-positive myofibroblasts (45). Collagen I is a key component of the ECM. In the process of EMT, tubular epithelial cells acquire the myofibroblast marker $\alpha$-SMA and vimentin, display a myofibroblastic morphology and secrete interstitial matrix components such as collagen I and fibronectin (8). Previous studies have demonstrated that selective blockade of tubular EMT may protect the kidneys from developing fibrotic lesions following obstructive injury (46), and that tubular EMT has an important role in renal tubulointerstitial fibrosis $(8,10,47)$. 
A
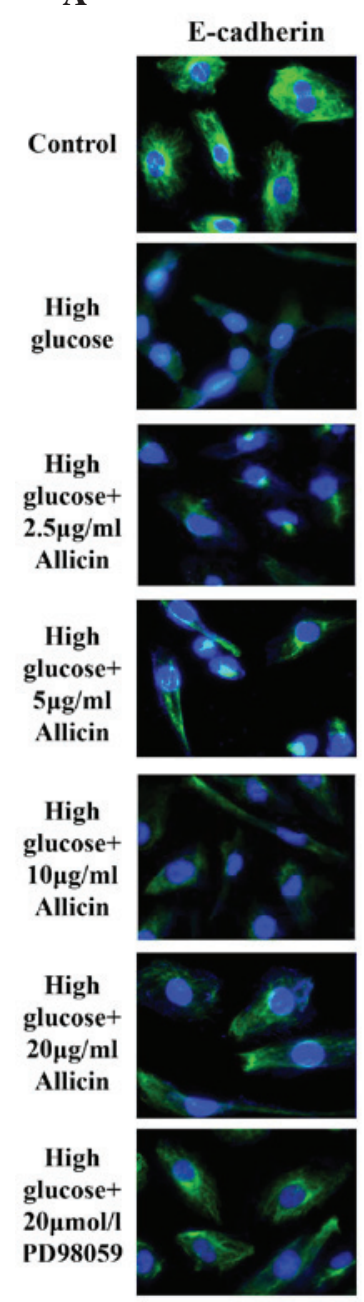

a-SMA
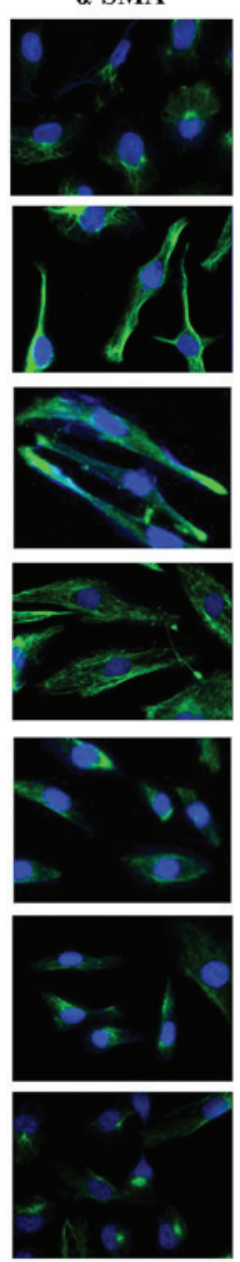
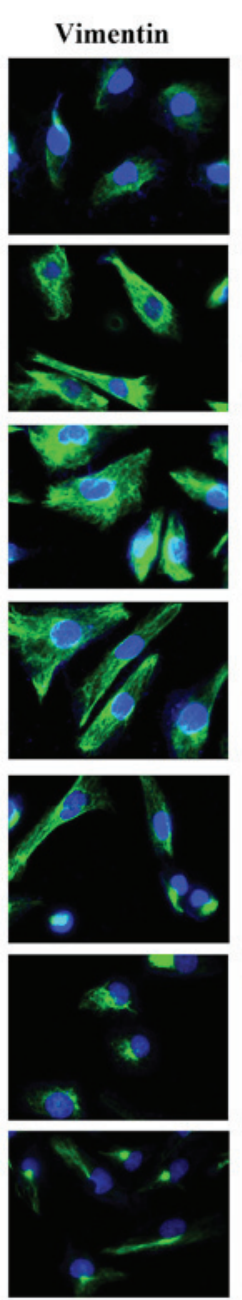
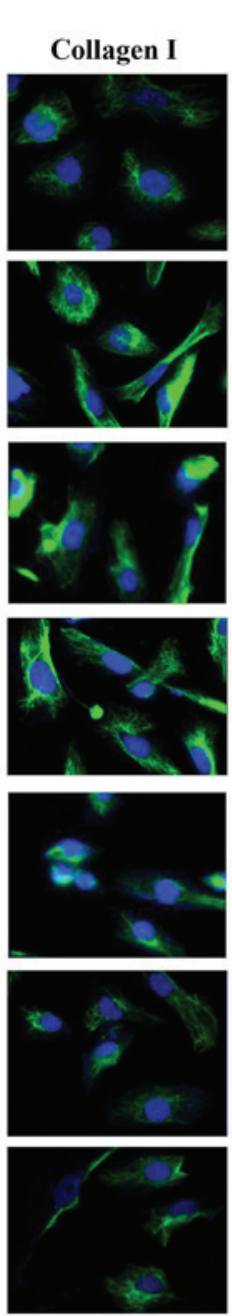

B
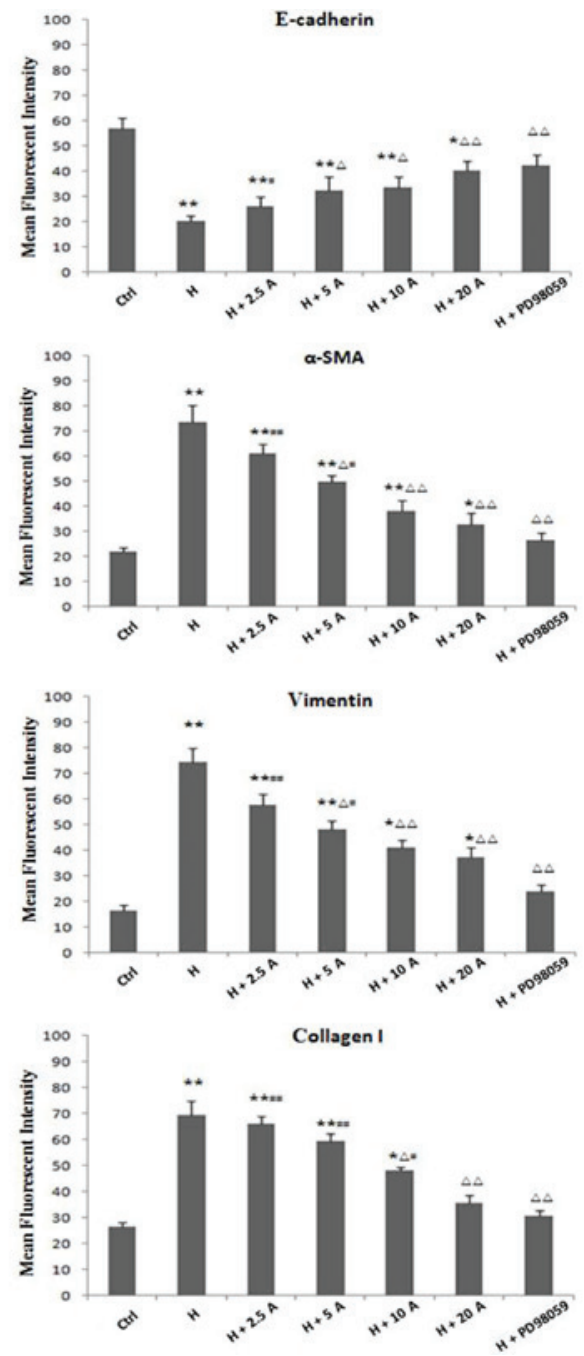

Figure 4. Expression of E-cadherin, $\alpha$-SMA, vimentin and collagen I in HK-2 cells. (A) Fluorescein isothiocyanate-labeled proteins are shown in green; DAPI-labeled nuclei are shown in blue. Cells were exposed to normal glucose (ctrl), high glucose, high glucose plus 5 or $2.5,5$, 10 and $20 \mu \mathrm{g} / \mathrm{ml}$ allicin or high glucose plus $20 \mu \mathrm{mol} / 1 \mathrm{PD} 98059$ for $48 \mathrm{~h}$, as detected by fluorescence immunohistochemistry (magnification, $\mathrm{x} 400$ ). (B) Statistical analysis is also shown. ${ }^{*}<0.05$ and ${ }^{* *} \mathrm{P}<0.01$ vs. $\mathrm{Ctrl} ;{ }^{\Delta} \mathrm{P}<0.05$ and ${ }^{\Delta \Delta} \mathrm{P}<0.01$ vs. $\mathrm{H} ;{ }^{*} \mathrm{P}<0.05$ and ${ }^{\# \#} \mathrm{P}<0.01$ vs. $\mathrm{H}+\mathrm{PD} 98059$. $\alpha$-SMA, $\alpha$-smooth muscle actin; Ctrl, control; $\mathrm{H}$, high glucose; A, allicin.

Therefore, a potentially effective therapeutic strategy for progressive renal fibrosis may involve the prevention of tubular EMT in the diseased kidney.

TGF- $\beta 1$ is a key mediator responsible for transdifferentiation in vivo and in vitro $(7,46,48,49)$. It has previously been shown that TGF- $\beta 1$ has an important role in altering the phenotype of renal epithelial cells, and that this significantly contributes to the profibrotic effects (50). Previous studies have demonstrated that advanced glycation end products, which accumulate in the diabetic kidney, are powerful mediators of EMT (51), and act via TGF- $\beta 1$-dependent pathways involving various intracellular signaling molecules, including Smad and MAPK, in response to high glucose conditions $(51,52)$. Our previous study reported overexpression of TGF- $\beta 1$ during the EMT of renal tubular epithelial cells in a diabetic rat model (53). In the present study, it was shown that high glucose concentrations induced the EMT of HK-2 cells and significantly increased the expression levels of TGF- $\beta 1$ and collagen I. These results suggested that the tubular EMT and increased ECM synthesis induced by hyperglycemia may at least partly depend on TGF- $\beta 1$, while increased TGF- $\beta 1$ secretion following transdifferentiation may form a positive feedback loop. Therefore, TGF- $\beta 1$ may represent an additional key component of the pathway leading to EMT.

Activation of the Smad and/or MAPK signaling pathways is required for TGF- $\beta 1$-induced EMT (54). In addition, phosphorylation of ERK1/2, a downstream signaling molecule of TGF- $\beta 1$, is required for an optimal response to TGF- $\beta 1$ (55). Rhyu et al (18) reported that PD98059, a specific inhibitor of the MAPK/ERK kinase signaling pathway, was able to effectively inhibit the TGF- $\beta 1$-induced EMT process in NRK52E cells. In the present study, high glucose conditions activated the ERK1/2/MAPK and TGF- $\beta$ signaling pathways in the process of EMT. Previous studies have demonstrated that high glucose induces ERK1/2 phosphorylation in vitro and in vivo $(56,57)$. Furthermore, high glucose-mediated activation of p-ERK1/2 and high-glucose induced EMT were shown to be blocked by PD98059 (58). These results suggested that blockade of high glucose-mediated activation of the ERK1/2/MAPK signaling pathway was able to inhibit the EMT, a critical process in renal tubulointerstitial fibrosis (59). Further studies are required in order to validate that high glucose mediates EMT via the 

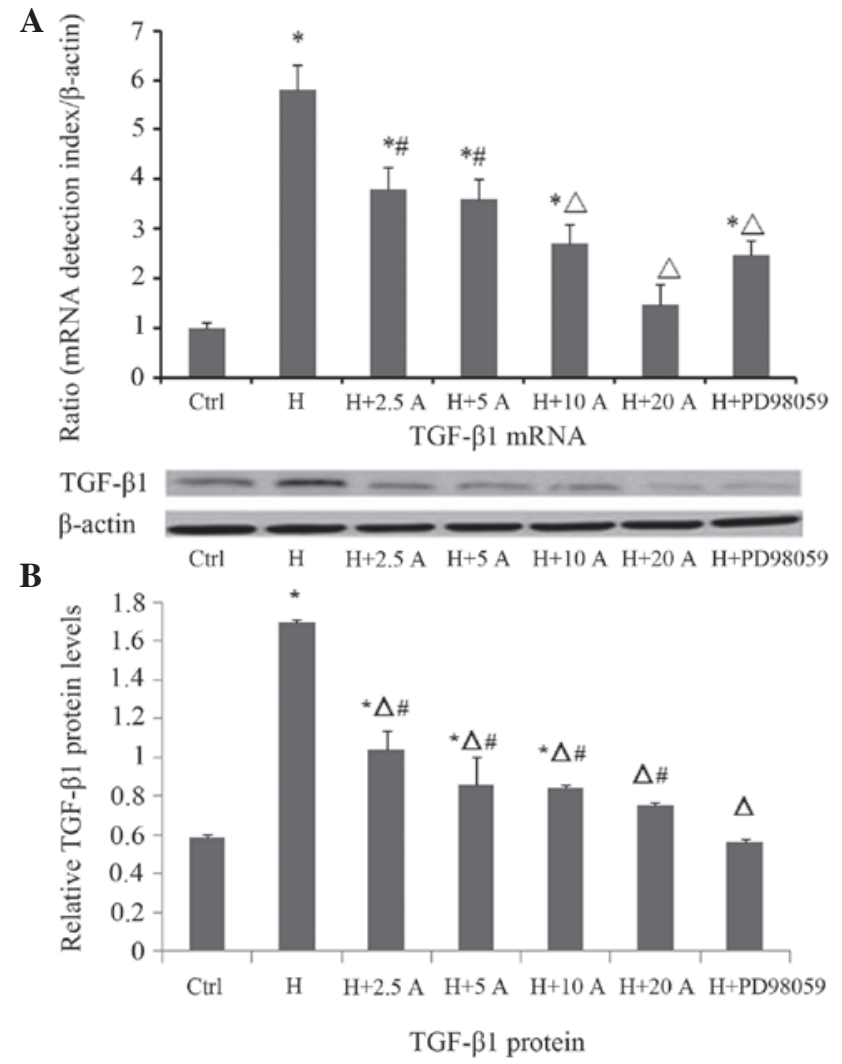

Figure 5. Allicin $(2.5,5,10$ or $20 \mu \mathrm{g} / \mathrm{ml})$ and PD98059 $(20 \mu \mathrm{mol} / \mathrm{l})$ reversed the high glucose-induced upregulation of TGF- $\beta 1 \mathrm{mRNA}$ and protein expression levels in HK-2 cells at $48 \mathrm{~h}$. The (A) mRNA and (B) protein expression levels of TGF- $\beta 1$ were determined by reverse transcription-quantitative polymerase chain reaction and western blotting, respectively. Data are presented as the mean \pm standard error of the mean. ${ }^{*} \mathrm{P}<0.05$ vs. the control; ${ }^{\Delta} \mathrm{P}<0.05$ vs. the high glucose group; ${ }^{~} \mathrm{P}<0.05$ vs. $\mathrm{PD} 98059$. TGF- $\beta 1$, transforming growth factor- $\beta 1$.

ERK/MAPK and TGF- $\beta 1$ signaling pathways, which are involved in numerous intracellular processes.

Allicin, which is a major active component isolated from garlic, has been used as a popular folk medicine for thousands of years (60). Allicin has previously been shown to inhibit fibroblast proliferation and collagen synthesis by regulating the TGF- $\beta$ signaling pathway, and inhibited myocardial fibrosis caused by abdominal aortic coarctation via its inhibition of myocardial collagen $(33,34)$. In a rat model of liver fibrosis, allicin was able to significantly inhibit the transdifferentiation of stellate cells to myofibroblasts via the downregulation of TGF- $\beta 1$ expression (35). Zhang et al (36) demonstrated that allicin significantly attenuated the development of myocardial fibrosis and exerted significant anti-proliferative effects in rabbit arterial smooth muscle cells induced by angiotensin II in a dose- and time-dependent manner. These findings suggested that allicin may have a role in the prevention of tissue fibrosis. However, whether allicin has a role in preventing renal fibrosis remains unknown.

The present study demonstrated that allicin was able to block the EMT and decrease the expression levels of collagen I in HK-2 cells cultured under high glucose conditions. Notably, $25 \mathrm{mM}$ glucose was able to induce the transdifferentiation of tubular cells into myofibroblasts that showed fibroblast-like morphologies, a loss of E-cadherin epithelial marker expression
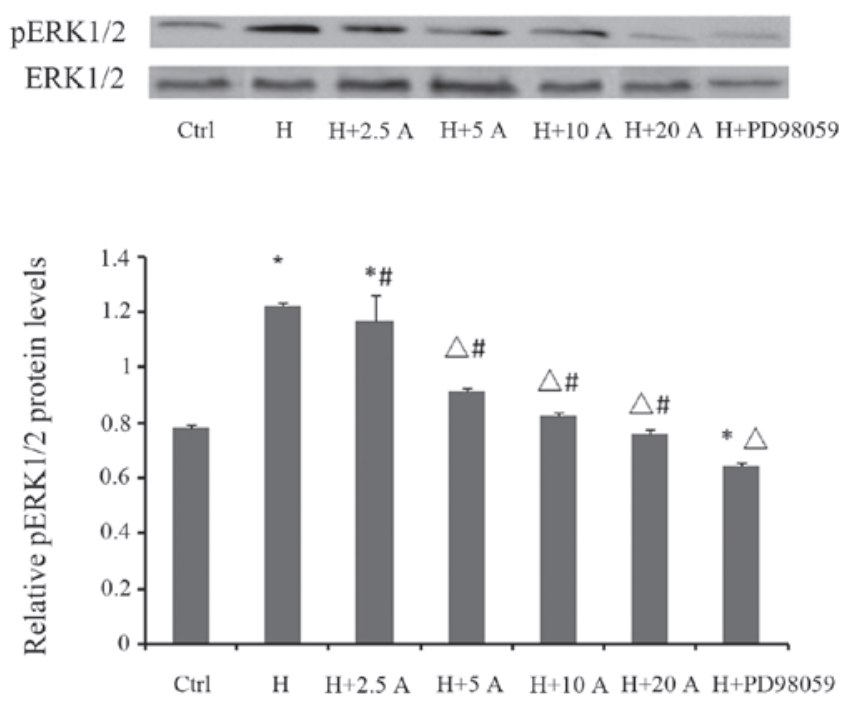

pERK1/2 protein

Figure 6. Allicin $(2.5,5,10$ or $20 \mu \mathrm{g} / \mathrm{ml})$ and PD98059 $(20 \mu \mathrm{mol} / \mathrm{l})$ reversed the high glucose-induced upregulation of $\mathrm{p}$-ERK1/2 protein expression in HK-2 cells at $48 \mathrm{~h}$, as shown by western blotting and densitometry. Data are presented as the mean \pm standard error of the mean. ${ }^{*} \mathrm{P}<0.05$ vs. the control; ${ }^{\wedge} \mathrm{P}<0.05$ vs. the high glucose group; ${ }^{*} \mathrm{P}<0.05$ vs. PD98059. p-ERK1/2, phosphorylated-extracellular signal regulated kinase $1 / 2$.

and $\alpha$-SMA and vimentin positivity. In addition, collagen I expression was shown to be increased in high glucose-induced HK-2 cells, which indicated that the transformed cells had begun to produce components of the ECM. Importantly, allicin treatment increased the expression of E-cadherin, prevented the de novo expression of $\alpha$-SMA and vimentin, and reduced collagen I expression in a dose-dependent manner. Furthermore, the present study demonstrated that simultaneous incubation of HK-2 cells with allicin markedly decreased the expression of p-ERK1/2 at $48 \mathrm{~h}$ in a dose-dependent manner, in particular at $20 \mu \mathrm{g} / \mathrm{ml}$. In addition, allicin reduced the expression of TGF- $\beta 1$, potentially by inhibiting the high glucose-mediated activation of the ERK1/2 signaling pathway, thereby inhibiting HK-2 cell morphological changes, the EMT and ECM synthesis, and resulting in the attenuation of tubular fibrosis.

In conclusion, the present study demonstrated that high glucose concentrations induced the EMT of renal tubule epithelial cells, and this was associated with upregulation of TGF- $\beta 1$ and collagen I. In addition, it was shown that the MAPK inhibitor PD98059 was able to reverse high glucose-induced transdifferentiation of HK-2 cells by inhibiting the expression of p-ERK $1 / 2$ and TGF- $\beta 1$. These results suggested that TGF- $\beta 1$ is an important regulator of the EMT and that ERK1/2 signaling pathway may be involved in renal interstitial fibrosis associated with DN. Furthermore, allicin treatment restrained the EMT and prevented subsequent interstitial matrix accumulation in vitro. However, further studies are required in order to clarify the effects of allicin on renal fibrosis.

\section{Acknowledgements}

The present study was supported by the National Natural Science Foundation of China (grant no. 81270924) and the 
Major Science Technology Program of Zhejiang Province (grant no. 2009C03010-4).

\section{References}

1. Liu Y: Renal fibrosis: New insights into the pathogenesis and therapeutics. Kidney Int 69: 213-217, 2006.

2. Lee JH, Kim JH, Kim JS, Chang JW, Kim SB, Park JS and Lee SK: AMP-activated protein kinase inhibits TGF- $\beta-$, angiotensin II-, aldosterone-, high glucose-, and albumin-induced epithelial-mesenchymal transition. Am J Physiol Renal Physiol 304: F686-F697, 2013.

3. Wang WC, Liu SF, Chang WT, Shiue YL, Hsieh PF, Hung TJ, Hung CY, Hung YJ, Chen MF and Yang YL: The effects of diosgenin in the regulation of renal proximal tubular fibrosis. Exp Cell Res 323: 255-262, 2014

4. Wei J, Shi Y, Hou Y, Ren Y, Du C, Zhang L, Li Y and Duan H: Knockdown of thioredoxin-interacting protein ameliorates high glucose-induced epithelial to mesenchymal transition in renal tubular epithelial cells. Cell Signal 25: 2788-2796, 2013

5. Ban CR and Twigg SM: Fibrosis in diabetes complications: Pathogenic mechanisms and circulating and urinary markers. Vasc Health Risk Manag 4: 575-596, 2008.

6. Simonson MS: Phenotypic transitions and fibrosis in diabetic nephropathy. Kidney Int 71: 846-854, 2007.

7. Burns WC and Thomas MC: The molecular mediators of type 2 epithelial to mesenchymal transition (EMT) and their role in renal pathophysiology. Expert Rev Mol Med 12: e17, 2010.

8. Liu Y: Epithelial to mesenchymal transition in renal fibrogenesis: Pathologic significance, molecular mechanism, and therapeutic intervention. J Am Soc Nephrol 15: 1-12, 2004.

9. Kalluri R and Neilson EG: Epithelial-mesenchymal transition and its implications for fibrosis. J Clin Invest 112: 1776-1784, 2003.

10. Rastaldi MP, Ferrario F, Giardino L, Dell'Antonio G, Grillo C Grillo P, Strutz F, Müller GA, Colasanti G and D'Amico G: Epithelial-mesenchymal transition of tubular epithelial cells in human renal biopsies. Kidney Int 62: 137-146, 2002.

11. Liu Y and Yang J: Hepatocyte growth factor: New arsenal in the fights against renal fibrosis? Kidney Int 70: 238-240, 2006.

12. Gonzalez DM and Medici D: Signaling mechanisms of the epithelial-mesenchymal transition. Sci Signal 7, 2014

13. Li Y, Zhang J, Fang L, Luo P, Peng J and Du X: Lefty A attenuates the TGF-betal-induced epithelial to mesenchymal transition of human renal proximal epithelial tubular cells. Mol Cell Biochem 339: 263-270, 2010.

14. Wang W, Koka V and Lan HY: Transforming growth factor-beta and Smad signalling in kidney diseases. Nephrology (Carlton) 10: 48-56, 2005 .

15. El Mesallamy HO, Ahmed HH, Bassyouni AA and Ahmed AS: Clinical significance of inflammatory and fibrogenic cytokines in diabetic nephropathy. Clin Biochem 45: 646-650, 2012.

16. Zhang $\mathrm{W}$ and Liu H: MAPK signal pathways in the regulation of cell proliferation in mammalian cells. Cell Research 12: 9-18, 2002.

17. Jang HS, Han SJ, Kim JI, Lee S, Lipschutz JH and Park KM Activation of ERK accelerates repair of renal tubular epithelial cells, whereas it inhibits progression of fibrosis following ischemia/ reperfusion injury. Biochim Biophys Acta 1832: 1998-2008, 2013

18. Rhyu DY, Yang Y, Ha H, Lee GT, Song JS, Uh ST and Lee HB: Role of reactive oxygen species in TGF-beta1-induced mitogen-activated protein kinase activation and epithelial-mesenchymal transition in renal tubular epithelial cells. J Am Soc Nephrol 16: 667-675, 2005

19. Ali M, Thomson M and Afzal M: Garlic and onions: Their effect on eicosanoid metabolism and its clinical relevance. Prostaglandins Leukot Essent Fat Acids 62: 55-73, 2000.

20. Cutler RR and Wilson P: Antibacterial activity of a new, stable, aqueous extract of allicin against methicillin-resistant staphylococcus aureus. Br J Biomed Sci 61: 71-74, 2004.

21. Goncagul G and Ayaz E: Antimicrobial effect of garlic (Allium sativum). Recent Pat Antiinfect Drug Discov 5: 91-93, 2010

22. Davis SR: An overview of the antifungal properties of allicin and its breakdown products-the possibility of a safe and effective antifungal prophylactic. Mycoses 48: 95-100, 2005.

23. Ramoutar RR and Brumaghim JL: Antioxidant and anticancer properties and mechanisms of inorganic selenium, oxo-sulfur and oxo-selenium compounds. Cell Biochem Biophys 58: 1-23, 2010 .
24. Elkayam A, Mirelman D, Peleg E, Wilchek M, Miron T, Rabinkov A, Sadetzki S and Rosenthal T: The effects of allicin and enalapril in fructose-induced hyperinsulinemic hyperlipidemic hypertensive rats. Am J Hypertens 14: 377-381, 2001.

25. Eilat S, Oestraicher Y, Rabinkov A, Ohad D, Mirelman D, Battler A, Eldar M and Vered Z: Alteration of lipid profile in hyperlipidemic rabbits by allicin, an active constituent of garlic. Coron Artery Dis 6: 985-990, 1995.

26. Abramovitz D, Gavri S, Harats D, Levkovitz H, Mirelman D, Miron T, Eilat-Adar S, Rabinkov A, Wilchek M, Eldar M and Vered Z: Allicin-induced decrease in formation of fatty streaks (atherosclerosis) in mice fed a cholesterol-rich diet. Coron Artery Dis 10: 515-519, 1999.

27. Gonen A, Harats D, Rabinkov A, Miron T, Mirelman D, Wilchek M, Weiner L, Ulman E, Levkovitz H, Ben-Shushan D and Shaish A: The antiatherogenic effect of allicin: Possible mode of action. Pathobiology 72: 325-334, 2005.

28. Lang A, Lahav M, Sakhnini E, Barshack I, Fidder HH, Avidan B, Bardan E, Hershkoviz R, Bar-Meir S and Chowers Y: Allicin inhibits spontaneous and TNF-alpha induced secretion of proinflammatory cytokines and chemokines from intestinal epithelial cells. Clin Nutr 23: 1199-1208, 2004.

29. Antony ML and Singh SV: Molecular mechanisms and targets of cancer chemoprevention by garlic-derived bioactive compound diallyl trisulfide. Indian J Exp Biol 49: 805-816, 2011.

30. Nagini S: Cancer chemoprevention by garlic and its organosulfur compounds-panacea or promise? Anticancer Agents Med Chem 8: 313-321, 2008

31. Park BJ, Cho SJ, Kwon HC, Lee KR, Rhee DK and Pyo S: Caspase independent cell death by allicin in human epithelial carcinoma cells: Involvement of PKA. Cancer Lett 224: 123-132, 2005.

32. Oommen S, Anto RJ, Srinivas G and Karunagaran D: Allicin (from garlic) induces caspase-mediated apoptosis in cancer cells. Eur J Pharmacol 485: 97-103, 2004.

33. Zhang HX, Shi ZX and Jia HZ: Effect of allicin on NIH3T3 cells on the proliferation and collagen synthesis. Zhong Guo Zhong Xi Yi Jie He Za Zhi 27: 431-434, 2007 (In Chinese).

34. Zhang HX, Jia HZ and Li G: Effect of allicin on myocardial fibrosis in rats with pressure overload. Zhong guo Zhong Yi Ji Chu Yi Xue 14: 149-151, 2008 (In Chinese)

35. Zhu LX, Cheng WC and Liu SZ: Effect of allicin on experimental hepatic fibrosis in rats. Chin J Dig Dis 7: 441-443, 2003.

36. Zhang DX, Ren YS and Liu B: Effect of allicin on angiotensin II-induced vascular smooth muscle cell proliferation. Zhong Guo Xiandai Yi Xue Za Zhi 15: 2136-2138, 2005 (In Chinese).

37. Zhu LX, Chen WC, Liu SZ and Gu ZL: Effect of allicin on experimental liver fibrosis in rats. Chin J Digest 23: 441-443, 2003 (In Chinese)

38. Xu C, Ding W, Zhang M and Gu Y: Protective effects of angiotensin-(1-7) administered with an angiotensin-receptor blocker in a rat model of chronic kidney disease. Nephrology (Carlton) 18: 761-769, 2013

39. Livak KJ and Schmittgen TD: Analysis of relative gene expression data using real-time quantitative PCR and the 2(-Delta Delta C(T)) Method. Methods 25: 402-408, 2001.

40. Liu J, Ma KL, Zhang Y, Wu Y, Hu ZB, Lv LL, Tang RN, Liu H, Ruan XZ, and Liu BC: Activation of mTORC1 disrupted LDL receptor pathway: A potential new mechanism for the progression of non-alcoholic fatty liver disease. Int J Biochem Cell Biol 61: 8-19, 2015.

41. Lee JM, Dedhar S, Kalluri R and Thompson EW: The epithelial-mesenchymal transition: New insights in signaling, development and disease. J Cell Biol 172: 973-981, 2006.

42. Strutz F, Okada H, Lo CW, Danoff T, Carone RL, Tomaszewski JE and Neilson EG: Identification and characterization of a fibroblast marker: FSP1. J Cell Biol 130: 393-405, 1995.

43. Barnes JL and Glass WF: Renal Interstitial Fibrosis: A Critical Evaluation of the Origin of Myofibroblasts. Contrib Nephrol 169: 73-93, 2011.

44. Iwano M, Plieth D, Danoff TM, Xue C, Okada H and Neilson EG: Evidence that fibroblasts derive from epithelium during tissue fibrosis. J Clin Invest 110: 341-350, 2002.

45. Li MX and Liu BC: Epithelial to mesenchymal transition in the progression of tubulointerstitial fibrosis. Chin Med J (Engl) 120: 1925-1930, 2007.

46. Yang J and Liu Y: Blockage of tubular epithelial to myofibroblast transition by hepatocyte growth factor prevents renal interstitial fibrosis. J Am Soc Nephrol 13: 96-107, 2002. 
47. Burns WC, Kantharidis P and Thomas MC: The role of tubular epithelial-mesenchymal transition in progressive kidney disease. Cells Tissues Organs 185: 222-231, 2007.

48. Fan JM, Huang XR, Ng YY, Nikolic-Paterson DJ, Mu W, Atkins RC and Lan HY: Interleukin-1 induces tubular epithelial- myofibroblast transdifferentiation through a transforming growth factor-beta1-dependent mechanism in vitro. Am J Kidney Dis 37: 820-831, 2001.

49. Jinde K, Nikolic-Paterson DJ, Huang XR, Sakai H, Kurokawa K, Atkins RC and Lan HY: Tubular phenotypic change in progressive tubulointerstitial fibrosis in human glomerulonephritis. Am J Kidney Dis 38: 761-769, 2001.

50. Lan HY: Tubular epithelial-myofibroblast transdifferentiation mechanisms in proximal tubule cells. Curr Opin Nephrol Hypertens 12: 25-29, 2003.

51. Oldfield MD, BachLA,Forbes JM,Nikolic-PatersonD, McRobert A Thallas V, Atkins RC, Osicka T, Jerums G and Cooper ME: Advanced glycation end products cause epithelial-myofibroblast transdifferentiation via the receptor for advanced glycation end products (RAGE). J Clin Invest 108: 1853-1863, 2001.

52. Li JH, Wang W, Huang XR, Oldfield M, Schmidt AM, Cooper ME and Lan HY: Advanced glycation end products induce tubular epithelial-myofibroblast transition through the RAGE-ERK1/2 MAP kinase signaling pathway. Am J Pathol 164: 1389-1397, 2004.

53. Ye X, Li H and Zhang JH: Phenotypic conversion of renal cortex cells in streptozotocin-induced diabetic rats. Zhong Guo Bing Li Sheng Li Za Zhi 23: 1645-1647, 2007 (In Chinese).
54. Liu RY,Zeng YY, Lei Z, Wang LQ, Yang HP, Liu ZY, Zhao J and Zhang HT: JAK/STAT3 signaling is required for TGF- $\beta$-induced epithelial-mesenchymal transition in lung cancer cells. Int J Oncol 2: 1643-1651, 2014

55. Nakerakanti $\mathrm{S}$ and Trojanowska $\mathrm{M}$ : The role of TGF- $\beta$ receptors in fibrosis. Open Rheumat J 6: 156-162, 2012.

56. Zhou L, Xue H, Yuan P, Ni J, Yu C, Huang Y and Lu LM: Angiotensin AT1 receptor activation mediates high glucose-induced epithelial-mesenchymal transition in renal proximal tubular cells. Clin Exp Pharmacol Physiol 37: e152-e157, 2010.

57. Cheng X, Gao W, Dang Y, Liu X, Li Y, Peng X and Ye X: Both ERK/MAPK and TGF-Beta/Smad signaling pathways play a role in the kidney fibrosis of diabetic mice accelerated by blood glucose fluctuation. J Diabetes Res 2013: 463740, 2013.

58. Dai B, Cui M, Zhu M, Su WL, Qiu MC and Zhang H: STAT1/3 and ERK1/2 synergistically regulate cardiac fibrosis induced by high glucose. Cell Physiol Biochem 32: 960-971, 2013.

59. Nakasatomi M, Maeshima A, Mishima K, Ikeuchi H, Sakairi T, Kaneko Y, Hiromura K and Nojima Y: Novel approach for the detection of tubular cell migration into the interstitium during renal fibrosis in rats. Fibrogenesis Tissue Repair 8: 12, 2015.

60. Block E: The chemistry of garlic and onions. Sci Am 252: $114-119,1985$. 